\title{
SECOND-ORDER ORDINARY DIFFERENTIAL EQUATIONS AND INCLUSIONS WITH A NEW KIND OF INTEGRAL AND MULTI-STRIP BOUNDARY CONDITIONS
}

\author{
Bashir Ahmad, Ahmed Alsaedi, Mona Alsulami \\ AND SOTIRIS K. NTOUYAS
}

\begin{abstract}
In this paper, we study the existence of solutions for nonlinear second-order ordinary differential equations and inclusions with nonlinearity depending upon the unknown function together with its first derivative, supplemented with a new kind of integral and multi-strip boundary conditions. Krasnoselskii fixed point theorem and Banach contraction mapping principle are employed to prove the existence and uniqueness results for the single-valued boundary value problem. In the multi-valued case the nonlinear alternative of Leray-Schauder type is the key tool for studying convex valued right-hand side, while the case of non-convex valued right-hand side is handled with the aid of a fixed point theorem for contractive multivalued maps due to Covitz and Nadler. Examples are constructed for the illustration of the obtained results.
\end{abstract}

Mathematics subject classification (2010): 34B10, 34B15, 34A60.

Keywords and phrases: Ordinary differential equations and inclusions, nonlocal, multi-strip, existence, fixed point.

\section{REFERENCES}

[1] B. Ahmad, A. Als aedi, B.S. Alghamdi, Analytic approximation of solutions of the forced Duffing equation with integral boundary conditions, Nonlinear Anal. Real World Appl. 9 (2008), 17271740.

[2] B. Ahmad, P.W. Eloe, Positive solutions of a nonlinear $n$th order boundary value problem with nonlocal conditions, Appl. Math. Lett. 18 (2005), 521-527.

[3] B. Ahmad, S.K. NTOUYAs, H.H. Alsulami, Existence results for $n$-th order multipoint integral boundary-value problems of differential inclusions, Electron. J. Differential Equations 2013, No. 203, $13 \mathrm{pp}$.

[4] B. Ahmad, S.K. NTOUyas, H.H. Alsulami, Existence of solutions or nonlinear $n$ th-order differential equations and inclusions with nonlocal and integral boundary conditions via fixed point theory, Filomat 28 (2014), 2149-2162.

[5] A. Alsaedi, M. Alsulami, R.P. Agarwal, B. Ahmad, Some new nonlinear second-order boundary value problems on an arbitrary domain, Adv. Difference Equ. (2018), 2018:227.

[6] H. Akca, V. Covachev, Z, Covacheva, Existence theorem for a second-order impulsive functional-differential equation with a nonlocal condition, J. Nonlinear Convex Anal. 17 (2016), 11291136.

[7] A. BOUCHERIF, Second-order boundary value problems with integral boundary conditions, Nonlinear Anal. TMA. 70 (2009), 364-371.

[8] M. Boukrouche, D.A. TARZIA, A family of singular ordinary differential equations of the third order with an integral boundary condition, Bound. Value Probl. (2018), 2018:32.

[9] J.R. CANNON, The solution of the heat equation subject to the specification of energy, Quart. Appl. Math. 21 (1963), 155-160.

[10] C. Castaing, M. Valadier, Convex Analysis and Measurable Multifunctions, Lecture Notes in Mathematics 580, Springer-Verlag, Berlin-Heidelberg-New York, 1977. 
[11] S. Clark, J. Henderson, Uniqueness implies existence and uniqueness criterion for non local boundary value problems for third-order differential equations, Proc. Amer. Math. Soc. 134 (2006), 3363-3372.

[12] H. Covitz, S. B. NADLER JR., Multivalued contraction mappings in generalized metric spaces, Israel J. Math. 8 (1970), 5-11.

[13] K. Deimling, Nonlinear Functional Analysis, Springer-Verlag, New York, 1985.

[14] K. Deimling, Multivalued Differential Equations, Walter De Gruyter, Berlin-New York, 1992.

[15] J. Dugundu, A. Granas, Fixed Point Theory, Springer-Verlag, New York, 2003.

[16] F.T. FEn, I. Y. KARACA, Positive solutions of nth-order boundary value problems with integral boundary conditions, Math. Model. Anal. 20 (2015), 188-204.

[17] M. FENG, W. GE, X. ZHANG, Existence theorems for a second order nonlinear differential equation with nonlocal boundary conditions and their applications, J. Appl. Math. Comput. 33 (2010), $137-$ 153.

[18] J.R. GRAEF, J.R.L. WeBB, Third order boundary value problems with nonlocal boundary conditions, Nonlinear Anal. 71 (2009), 1542-1551.

[19] C.P. GUPTA, Solvability of a three-point nonlinear boundary value problem for a second order ordinary differential equations, J. Math. Anal. Appl. 168 (1998), 540-551.

[20] J. HENDERSON, Smoothness of solutions with respect to multi-strip integral boundary conditions for $n$th order ordinary differential equations, Nonlinear Anal. Model. Control 19 (2014), 396-412.

[21] Sh. Hu, N. Papageorgiou, Handbook of Multivalued Analysis, Volume I: Theory, Kluwer, Dordrecht, 1997.

[22] T. Hughes, C. TAYlor, C. Zarins, Finite element modeling of blood flow in arteries, Comput. Methods Appl. Mech. Engrg. 158 (1998), 155-196.

[23] V.A. IL'IN, E.I. MoISEEV, Nonlocal boundary-value problem of the first kind for a Sturm-Liouville operator in its differential and finite difference aspects, Differential Equations 23 (1987), 803-810.

[24] G. Infante, J. R. L. WebB, Positive solutions of nonlocal boundary value problems: A unified approach, J. London Math. Soc. 74 (2006), 673-693.

[25] G. Infante, J. R. L. WebB, Positive solutions of nonlocal boundary value problems involving integral conditions, NoDEA, Nonlinear Differ. Equ. Appl. 15 (2008), 45-67.

[26] N.I. IONKIN, The solution of a certain boundary value problem of the theory of heat conduction with a nonclassical boundary condition (Russian), Diff. Uravn. 13 (1977), 294-304.

[27] M. Kisielewicz, Differential Inclusions and Optimal Control, Kluwer, Dordrecht, The Netherlands, 1991.

[28] A. Lasota, Z. Opial, An application of the Kakutani-Ky Fan theorem in the theory of ordinary differential equations, Bull. Acad. Polon. Sci. Ser.Sci. Math. Astronom. Phys. 13 (1965), 781-786.

[29] Y. LI, H. ZHANG, Positive solutions for a nonlinear higher order differential system with coupled integral boundary conditions, J. Appl. Math. 2014, Art. ID 901094, 7 pp.

[30] D. Maroncelli, J. RodrigueZ, Existence theory for nonlinear Sturm-Liouville problems with nonlocal boundary conditions, Diff. Equ. Appl. 10 (2018), 147-161.

[31] S.K. NTOUYAs, Nonlocal Initial and Boundary Value Problems: A survey, Handbook on Differential Equations: Ordinary Differential Equations, Edited by A. Canada, P. Drabek and A. Fonda, Elsevier Science B. V., 2005, 459-555.

[32] D.R. SMART, Fixed Point Theorems, Cambridge University Press, 1980.

[33] S. WANG, Multiple positive solutions for nonlocal boundary value problems with $p$-Laplacian operator, Differ. Equ. Appl. 9 (2017), no. 4, 533-542.

[34] L. ZHENG, X. ZHANG, Modeling and analysis of modern fluid problems. Mathematics in Science and Engineering, Elsevier/Academic Press, London, 2017. 